\title{
Next generation of radio spectrum management: Licensed shared access for $5 \mathrm{G}$
}

\author{
Maria Massaro \\ Department of Technology Management and Economics, Chalmers University of Technology, Vera Sandbergs Allé 8, 41296 Gothenburg, \\ Sweden
}

\section{A R T I C L E I N F O}

\section{Keywords:}

Licensed shared access

Spectrum access system

Spectrum sharing

Dynamic efficiency

$5 \mathrm{G}$

\begin{abstract}
A B S T R A C T
Deployment of 5th generation (5G) mobile communication technology is setting the stage for the next generation of radio spectrum management. New spectrum sharing arrangements have been identified as effective ways to satisfy emerging connectivity needs. In particular, the so-called Licensed Shared Access (LSA) regime has been given prominence in the European Union (EU) to facilitate access to additional spectrum necessary to meet the exponential growth of mobile data traffic. Under the LSA regime, already occupied, but underutilised spectrum would be shared, on a licensed-basis, between incumbents and mobile operators, under agreed frequency, location and time sharing conditions. A similar system has been proposed in the United States (US), called Spectrum Access System (SAS).

In this context, the purpose of this paper is two-fold: firstly, to assess the novelty of the LSA regime with respect to existing spectrum sharing arrangements in the EU and, secondly, to identify the main differences between the LSA and the SAS regimes. Policy documents, academic papers, position papers and analysis reports are scrutinised to gather information on technical and regulatory aspects of existing and emerging spectrum sharing regimes.

This paper concludes that the novelty of the LSA regime is found in the possibility for mobile operators to access additional spectrum below $6 \mathrm{GHz}(\mathrm{GHz})$ with the regulatory certainty required to invest in 5G. Implementing other spectrum sharing regimes to access sub- $6 \mathrm{GHz}$ spectrum would not guarantee mobile operators protection from harmful interference and predictable Quality of Service (QoS).

The comparison between the LSA and the SAS approaches suggests that the LSA regime can be implemented quicker and with less effort than the SAS regime, because of its lower level of technical complexity. Nevertheless, the LSA regime is expected to be overtaken by the SAS regime in the long term, as technology advances. The SAS regime would allow more users to coexist in the same spectrum bands thanks to spectrum sensing techniques.
\end{abstract}

\section{Introduction}

Demand for access to the radio spectrum is constantly and rapidly growing. In particular, more radio spectrum is needed to cope with an exponential growth of mobile data traffic (Khun-Jush, Bender, Deschamps \& Gundlach, 2012). According to a recent forecast, global mobile data traffic is expected to increase eightfold between 2015 and 2020, with a compound annual growth rate (CAGR) of 53 per cent. Global mobile data traffic would reach 30.6 exabytes per month by 2020, compared to 820 petabytes per

E-mail address: massaro@chalmers.se. 
month at the end of $2012^{1}$ (Cisco, 2014; Cisco 2016a). Additionally, the foreseen mobile data growth is not only due to the use of smartphones and tablets (RSPG, 2013), but also machine-to-machine (M2M) communications in industries such as transport, logistics, automotive, health, manufacturing, energy, media and entertainment (ITU, 2015a; ITU, 2015b; 5G Manifesto, 2016; EC, 2016a; FCC, 2016a). M2M communications are expected to register a fivefold growth between 2015 and 2020 , growing from 604 million in 2015 to 3.1 billion in 2020 (Cisco, 2016b).

$5 \mathrm{G}$ networks ${ }^{2}$ are expected to support and promote such massive growth of mobile data traffic. Although still not standardised, 5G technology would be provided with enhanced characteristics, compared to existing network technologies, which would satisfy various connectivity needs, such as high data capacity, high data rate, low latency, high reliability, massive device connectivity, mobility and low energy consumption (4G Americas, 2015; ITU, 2015a; Ericsson, 2016a; EC, 2016a; RSPG, 2016). In order to meet varying connectivity needs, $5 \mathrm{G}$ networks are expected to be highly heterogeneous, including both macro and small cells, multiple input multiple output (MIMO) schemes, and high capacity backhaul. The heterogeneity of 5G network will be supported by employing different spectrum bands, below $6 \mathrm{GHz}$, in particular below $1 \mathrm{GHz}$, and above $6 \mathrm{GHz}$ (ITU, 2015a; ITU, 2015c; EC, 2016a; PolicyTracker, 2016).

On one hand, low spectrum bands possess better propagation properties, which can serve applications that require highly robust performance, over long distances. On the other hand, using higher bands guarantees greater data capacity, although over short distances. The attractiveness of high spectrum bands is due to two main elements: wider bandwidth and global harmonisation. High spectrum bands, in particular in the millimetre wave range between 20 and $300 \mathrm{GHz}$, offer contiguous and wide spectrum bandwidth to support connectivity needs such as high data rate, low latency and high capacity, in specific areas where traffic demand is very high. Spectrum blocks in higher bands would be at least $100 \mathrm{MHz}$ in width, while spectrum blocks in low bands are usually $5-$ $10 \mathrm{MHz}$ in width (4G Americas, 2015; Wheeler, 2016). In addition, high spectrum bands offer opportunities for global harmonisation. This would be extremely beneficial in terms of economies of scale in equipment manufacturing, reduced device complexity, and reduced cross-border interference.

Finding contiguous spectrum for mobile broadband services in the sub- $6 \mathrm{GHz}$ spectrum is challenging. Sub-6 GHz spectrum is particularly crowded as it is employed for several public and commercial uses, including mobile broadband services. Sub-6 GHz spectrum used for mobile broadband services is not globally harmonised (ITU, 2012a). On the contrary, its availability and amount of bandwidth vary across bands and countries. Spectrum fragmentation may prevent 5G from meeting the connectivity demands of certain use cases. Nevertheless, re-farming does not appear to be an appropriate solution when spectrum is highly fragmented (Cave \& Webb, 2015; Tehrani, Vahid, Triantafyllopoulou, Lee \& Moessner, 2016). Freeing up spectrum bands from current uses would result in an unreasonably costly and time-consuming process (Khun-Jush et al., 2012). At the same time, evidence shows that parts of the sub- $6 \mathrm{GHz}$ spectrum are underutilised. In the search for alternatives to spectrum re-farming, policy makers and regulators have identified new spectrum sharing arrangements as potential effective ways to access spectrum below $6 \mathrm{GHz}$ in a timely manner (Nicita \& Rossi, 2013). In addition to licence-exempt shared access, the new concept of shared access on a licensed basis has been investigated, in particular in the EU and the US (EC, 2012; Mueck et al., 2015; FCC, 2015; AGCOM, 2016a).

The licence-exempt shared access regime has existed for long time (Cave \& Webb, 2015). Under this regime, anyone is authorised to use the spectrum, as long as compliance with certain technical measures, necessary to minimise the risk of producing harmful interference, is guaranteed (Faulhaber \& Farber, 2002). A larger number of users can access the spectrum, compared to exclusive access regimes. Nevertheless, users cannot claim protection from harmful interference and there is no certainty over QoS. The need to guarantee protection from harmful interference and predictable QoS in the provision of mobile broadband services has motivated policy makers and regulators to develop new sharing regimes which could satisfy such needs.

In the EU, the LSA regime is currently under discussion. The LSA regime has been defined as a regulatory approach that allows for shared use of already assigned, but underused spectrum bands between incumbents and a limited number of new users, by means of individual spectrum rights of use. These individual licences would include sharing conditions to allow both incumbents and new users to provide guaranteed QoS. In the US, the SAS regime has been proposed. The SAS regime is a three-tier system of spectrum access, which broadly resembles the LSA architecture. The novelty of the LSA and the SAS regimes lays on the possibility to support spectrum sharing, while at the same time, providing spectrum users with individual spectrum rights of use. Since 2013, LSA trials have been conducted in a number of EU member states, including Italy, Spain, Finland and France to test the feasibility of such sharing arrangement in the $2.3 \mathrm{GHz}$ band (EC, 2012; ETSI, 2013; CEPT, 2014a; CEPT, 2014b; CEPT, 2016). Similarly, the SAS regime has recently attracted increasing attention from the industry, which has committed to invest considerable resources for its implementation in the $3.5 \mathrm{GHz}$ band (Wilkins \& Knapp, 2016).

Several studies argue for the implementation of spectrum sharing solutions, including the LSA regime, to promote dynamic efficiency in the telecommunications sector (Noam, 2003; Peha, 2009; Bunel \& Lescop, 2012; Khun-Jush et al., 2012; RSPG, 2013; Plum Consulting, 2013; Werbahc \& Mehta, 2014; Rysavy, 2014). Furthermore, promoting dynamic efficiency has become a key public policy priority worldwide (EC, 2015; EC, 2016b; EC, 2016c; Wheeler, 2016). A growing telecommunications sector not only directly generates economic and social growth, but also indirectly contributes to the development of other industries, such as transport, trade and construction industries (Bauer, 2010; Bauer \& Shim, 2012; Yang, Lee, Hwang \& Shin, 2013). Although there is no standardised definition of dynamic efficiency as radio spectrum regulatory principle, it can be said that dynamic efficiency occurs when the radio spectrum is managed in such a way that investment and innovation in radio-based technologies and services are

\footnotetext{
${ }^{1} 1$ petabyte corresponds to $10^{15}$ byte and 1 exabyte corresponds to $10^{18}$ byte.

${ }^{2}$ It has to be said that $5 \mathrm{G}$ relies on a combination of mobile and fixed technologies (EC, 2016a).
} 
Table 1

Overview of the three generations of radio spectrum management.

\begin{tabular}{llll}
\hline & FIRST GENERATION & SECOND GENERATION & THIRD GENERATION \\
\hline Policy Objectives & $\begin{array}{l}\text { Interference avoidance } \\
\text { International harmonisation }\end{array}$ & Efficient allocation (static efficiency) & Innovation and investment (dynamic efficiency) \\
Regulatory Approach & Administrative-based & Market-based & Technology-based \\
Assignment Procedure & First come-first served & Auctions & Leasing \\
& Beauty contests & Secondary trading & Licence-exempt \\
Spectrum & Individual exclusive access & Individual exclusive access & Individual shared access \\
Access & & & Unrestricted access \\
\hline
\end{tabular}

encouraged and competition in the markets where radio spectrum is a key resource is promoted (Cave, 2002; Cave et al., 2007; Bauer \& Bohlin, 2008).

Against this background, the purpose of this paper two-fold. Firstly, this paper wants to assess the novelty of the LSA regime with respect to existing spectrum sharing arrangements in the EU. Secondly, this paper wants to identify the main differences between the LSA and the SAS regimes in order to understand to what extent the EU and the US have adopted different strategies to reach the same objective of finding additional spectrum for mobile broadband services. Policy documents, academic papers, position papers and analysis reports are scrutinised to gather information on technical and regulatory aspects of existing and emerging spectrum sharing arrangements. The rest of this paper is structured as follows: in Section 2, the evolution of radio spectrum management is articulated in three generations. This section serves as contextual background to understand the current interest in spectrum sharing. Section 3 compares the LSA regime with the Collective Use of Spectrum (CUS) model, which encompasses other spectrum sharing arrangements adopted in the EU. In addition, the main differences between the LSA and the SAS regimes are highlighted. Section 4 concludes with few remarks on the relevance of licensed shared access to support 5G deployment.

\section{Three generations of radio spectrum management}

In the late 19th century, access to the radio spectrum and its conditions of use started to be regulated. Regulatory intervention was deemed crucial to tackle the issue of harmful interference, emerged as a consequence of increasing number and variety of radiobased services (Prasad \& Sridhar, 2014). Over time, three main generations of radio spectrum management have developed. It is worth stating that these generations are not mutually exclusive. On the contrary, their coexistence is justified by the necessity to accommodate diverse needs of various technologies and services. Table 1 shows some basic differences between the three generations, in terms of policy objectives and regulatory approaches, in particular with regard to assignment procedures and spectrum access. The three generations of radio spectrum management are further illustrated below.

\subsection{First generation: Administrative approach}

The first generation of spectrum management (Marcus et al., 2013) was introduced with the intent to minimise the risk of harmful interference and internationally harmonise the use of radio spectrum (McLean Foster \& Co, 2007). Several international, regional and national regulatory entities are currently in place to ensure interference-free provision of services. Furthermore, international harmonisation of radio spectrum use has been promoted since the beginning of radio spectrum regulation, because of significant benefits in terms of technology standardisation and economies of scale in equipment manufacturing (e.g. RSPG, 2015). This regime has been administrative-based, characterised by central planning and scarce flexibility in the regulatory decision-making process. Furthermore, radio spectrum licences have often been assigned free of charge, on a first come-first served basis, or by means of beauty contests (e.g. Melody \& Lemstra, 2011). In the latter case, applicants have been selected on the basis of a set of predefined criteria, including financial resources and network deployment plans. Over time, this administrative-based approach has revealed some significant flaws, including lack of economic rationales, political influence and long delays in assigning radio spectrum licences, as well as radio spectrum misallocations (e.g. Bauer, 2002). In the 1990s, a first wave of spectrum policy reforms unfolded to overcome the shortcomings of the administrative regime of the first generation.

\subsection{Second generation: Market-based approach}

A second generation of radio spectrum management emerged, whose main policy goal was to enhance static efficiency (Lie, 2004), i.e. guaranteeing a more efficient allocation of radio spectrum. The regulatory approach to radio spectrum shifted from being focused on central planning to relying on market forces. This is because of the neoclassical economic principle that perfect competition leads to efficient allocation of scarce resources (e.g. Sappington \& Weisman, 1996). Spectrum rights of use started to be assigned by means of auctions (Bauer, 2002), whereby licences are awarded on the basis of bidding among competing applicants. Generally, the bidder who offers the highest monetary sum receives the licence (ITU, 2012b). The key advantage of auction procedures is that licences are assigned to the users that bid the most, which are expected to be the ones who assign to spectrum the highest value (e.g. Cave, 2002; Lie, 2004).

Also, markets for spectrum rights of use have been established, to allow for a change of ownership by secondary trading (McLean 
Foster \& Co., 2007). The belief was that tradability of rights of use would have promoted efficient allocation of radio spectrum over time (Cambini \& Garelli, 2011). Yet, Noam (1998 and 2003) and Oniki (2009) anticipated the limitations of market mechanisms as an efficient spectrum assignment tool. Although considered more efficient compared to administrative assignment procedures, market mechanisms have revealed their drawbacks. In particular, auctions have sometimes led bidders overpay for spectrum licences; they have been used by governments as an instrument to extract revenues from auction participants (e.g. GSMA, 2014) and by incumbents to preserve their status quo and fend off new entrants. In addition, secondary trading has not taken off as much as policy-makers and regulators had hoped. Furthermore, evidence shows that large portions of assigned spectrum are currently underused, foreclosing opportunities for alternative services to access the spectrum (Peha, 2009).

The current radio spectrum environment, characterised by fast changes in technology and market conditions, is setting the stage for a second wave of spectrum policy reforms. The current debate among policy makers and regulators is to adopt a more flexible management approach to radio spectrum, which is considered necessary to promote investments and innovation in mobile communications technologies and services (EC, 2016a; EC, 2016b; FCC, 2015; Wheeler, 2016). A third generation of radio spectrum management is envisaged, characterised by a shift of policy focus from static to dynamic efficiency.

\subsection{Third generation: Technology-based approach}

This new generation of radio spectrum management stands out from previous generations for its stronger focus on technology developments. Although some forms of spectrum sharing have been implemented for long time, since spectrum access started to be regulated (Cave \& Webb, 2015), more sophisticated radio equipment and refined technical and operational conditions are bringing opportunities for new ways of sharing spectrum. In particular, policy and regulatory bodies in the EU and the US, are working on new forms of spectrum sharing arrangements, which would enable shared access on a licensed basis.

In the EU, identification of radio frequency bands eligible for spectrum sharing was one of the key objectives of the Radio Spectrum Policy Programme (RSPP) (EP \& Council, 2012). In 2011, the Radio Spectrum Policy Group (RSPG) published an Opinion on cognitive technologies, highlighting the importance of intelligent technologies to share radio frequencies (RSPG, 2011a). In the same year, the RSPG published a report bringing forward a dynamic approach to spectrum sharing (RSPG, 2011b). Moreover, the European Commission (EC) Communication on "Promoting the shared use of radio spectrum resources in the internal market", published in 2012, identified radio spectrum sharing as the solution at the forefront to the problem of lack of available spectrum for new spectrum needs (EC, 2012). More recently, the need to share spectrum has been emphasised by the EC in the proposal for a directive of the European Parliament (EP) and the Council establishing the European Electronic Communications Code (EC, 2016b).

In the US, the idea of spectrum sharing has been extensively discussed since 2006, when the National Telecommunications and Information Administration (NTIA), in coordination with the Federal Communications Commission (FCC), examined the feasibility of spectrum sharing between federal and non-federal users (Federal Register, 2008). In 2012, the Citizens Broadband Radio Service initiative was proposed to accommodate mobile broadband services in the $3.5 \mathrm{GHz}$ band, which resulted underutilised by incumbent federal and non-federal users. In particular, three groups of users, incumbents, priority access users, and general authorised access users, would coexist in this band and their use of spectrum would be coordinated through the SAS regime (Leibovitz, 2015).

In the EU, two alternative sharing approaches are promoted: the Collective Use of Spectrum (CUS) and the Licensed Shared Access (LSA) (RSPG, 2009; 2011b and 2013). The main difference between these two approaches regards the type of authorisation scheme implemented. Service providers are subject to a general authorisation scheme under the CUS approach and to an individual authorisation scheme under the LSA approach (RSPG, 2011b). Under the general authorisation scheme, spectrum can be used without obtaining an individual licence. Anyone can access a certain spectrum band, as long as compliance with pre-defined conditions is guaranteed. Nevertheless, no protection from harmful interference can be claimed and users are not asked to selfcoordinate.

Under the individual authorisation scheme, access to radio spectrum is subject to the grant of individual licences by a National Regulatory Authority (NRA). An individual licence is an authorisation granted to access a specific radio frequency band, in a certain geographic area, for a certain period of time. A number of conditions are attached to individual licences in order to avoid the risk of producing harmful interference; ensure technical quality of service (QoS); avoid congestion problems; and fulfil specific national interests. In addition, individual licences can, in principle, be transferred or leased (EP \& Council, 2002; ECC, 2011).

It must be clarified that the CUS model includes two sharing regimes: the licence-exempt and the light licensing regimes. There is no standardised definition of the light licensing regime in the EU and its implementation varies from country to country. While the licence-exempt regime falls under the general authorisation scheme, the light licensing regime can be implemented under the general or the individual authorisation scheme. Under the individual authorisation scheme, users would obtain a licence to access the spectrum, which would grant the right of protection from harmful interference. No technical conditions would be attached to the licences to guarantee an interference-free spectrum use. Nevertheless, a new user, interfering with existing users, would be forced to suspend or correct its transmissions. Under the general authorisation scheme, users receive authorisations to access the spectrum, but no protection from harmful interference is guaranteed. It is mostly the users' responsibility to self-coordinate and manage interference effectively (Webb, 2008; ECC, 2009). The CUS and LSA approaches are further illustrated below.

\subsubsection{The CUS approach}

The CUS approach can be implemented in three different ways, as shown in Table 2. These three ways present more or less strict regulatory obligations, depending on the likelihood of interference issues.

In the first scenario, interference is not a concern and the CUS model allows for licence-exempt shared access, whereby access to 
Table 2

Three ways to implement the CUS approach: main characteristics.

Source: adapted from RSPG (2011b).

\begin{tabular}{|c|c|c|}
\hline LICENCE-EXEMPT & LICENCE-EXEMPT & LIGHT LICENSING \\
\hline Unrestricted access for any application & Unrestricted access for specific applications & $\begin{array}{l}\text { Unrestricted access until full capacity(first-come-first-served } \\
\text { principle) }\end{array}$ \\
\hline No notification/registration & No notification/registration & Registration/light licence \\
\hline $\begin{array}{l}\text { Compliance with pre-defined technical } \\
\text { criteria }\end{array}$ & $\begin{array}{l}\text { Compliance with pre-defined technical } \\
\text { criteria }\end{array}$ & Self-coordination \\
\hline No protection from harmful interference & No protection from harmful interference & Limited protection from harmful interference \\
\hline
\end{tabular}

radio spectrum is free of charge and it is not subject to any registration or notification procedure. Any application is permitted to use the spectrum band, as long as compliance with certain pre-defined criteria is guaranteed. These criteria are usually included in the national table of frequency allocations and generally regard the use of low power and short range devices. No protection from harmful interference can be claimed. This means that users cannot ask the NRA to intervene in order to solve interference issues, unless the interference is caused by applications which do not comply with the pre-defined criteria of use. In this case, the NRA can be asked to intervene (RSPG, 2011b; Faulhaber \& Farber, 2002).

In the second scenario, access to a licence-exempt frequency band is limited to specific types of services or technologies, for instance, related to safety or security of life. The necessity to limit access to licence-exempt bands has to be proven by conducting compatibility studies. The results of these studies should show that there is a risk that different applications using the same frequency band may interfere with one another or that certain applications would require higher transmission power (RSPG, 2011b). Similar to the first scenario, protection from harmful interference can be claimed only if the interference is caused by non-authorised services and technologies (RSPG, 2009).

In the third scenario, the light licensing regime is implemented to guarantee a certain degree of control over the use of spectrum. The light licensing regime requires spectrum users to register or notify their use of the spectrum and may also be asked to pay a small fee to cover the costs of registration or notification. The light licensing regime is based on a public database containing information on technical parameters, including location, frequency, power, and antenna type, of all registered users. New users are required to consult the database, before requesting to access the spectrum, in order to ensure that their use of the spectrum would not interfere with existing uses. Control over harmful interference is ensured by requesting users to self-coordinate, taking account of existing users registered in the database. The light licensing regime is usually implemented in situations where radio spectrum is not scarce and no interference issues are expected (Tehrani et al., 2016). Access to spectrum is not restricted to a pre-defined number of users. Nevertheless, interference issues may arise in the future, and this justifies the intent to keep track of spectrum use.

\subsubsection{The LSA approach}

The LSA approach has only recently been introduced in the EU regulatory framework for radio spectrum and its potential implications are being discussed by policy-makers (e.g. RSPG, 2013); industry (e.g. GSMA, 2013) and researchers (Palola, Matinmikko, Prokkola, Mustonen, Heikkilä \& eiska, 2014). The LSA regime was initially proposed as Authorised Shared Access (ASA) by an industry consortium composed by Qualcomm and Nokia. The aim was to allow the provision of mobile broadband services in already assigned spectrum bands, whenever and wherever they were unused by incumbent users (Ingenious Consulting Network, 2011). The ASA concept was extended to the notion of LSA by the RSPG, which recognised additional sharing opportunities to the case put forward by Qualcomm and Nokia (CEPT, 2013). The RSPG Opinion on LSA, approved in November 2013 (RSPG, 2013), defines the LSA concept as a "regulatory approach aiming to facilitate the introduction of radio communication systems operated by a limited number of licensees under an individual licensing regime in a frequency band already assigned or expected to be assigned to one or more incumbent users. Under the LSA approach, the additional users are authorised to use the spectrum (or part of the spectrum) in accordance with sharing rules included in their spectrum rights of use, thereby allowing all authorised users, including incumbents, to provide a certain QoS” (RSPG, 2013).

Access to already assigned, but underused spectrum bands would be granted to a limited number of new spectrum users, named LSA licensees, by means of individual spectrum rights of use. Existing users would lease part of their spectrum to new users, for a certain period of time, while maintaining control over the radio spectrum in the long term. Radio spectrum would be shared in terms of time, location and/or frequency, in accordance with a set of sharing rules (RSPG, 2013; Plum Consulting, 2013; Khun-Jush et al., 2012). These rules would include specific technical and operational requirements, for instance compatibility criteria, limitations of use, restriction/exclusion zones, and spectrum masks (RSPG, 2013; FUB, 2016). Incumbent users and LSA licensees would develop these sharing conditions in collaboration with the NRA, which would be responsible for the final approval (Khun-Jush et al., 2012; CEPT, 2013; RSPG, 2013; Plum Consulting, 2013). The sharing conditions would be included in the licences that the NRA assigns, once an agreement between incumbents and secondary users on how to share spectrum is reached.

As shown in Fig. 1, the LSA system would be based on the creation of two elements: the LSA repository and the LSA controller. The LSA repository includes sharing rules and information on incumbent spectrum use. The incumbent is responsible for providing the information to be included in the LSA repository, making sure that its information is up-to-date. The LSA controller retrieves information from the LSA repository and establishes spectrum availability for LSA licensees. The LSA repository could be managed by the NRA, the incumbent or a trusted third party. The LSA controller would most likely be managed by the LSA licensee, but could 

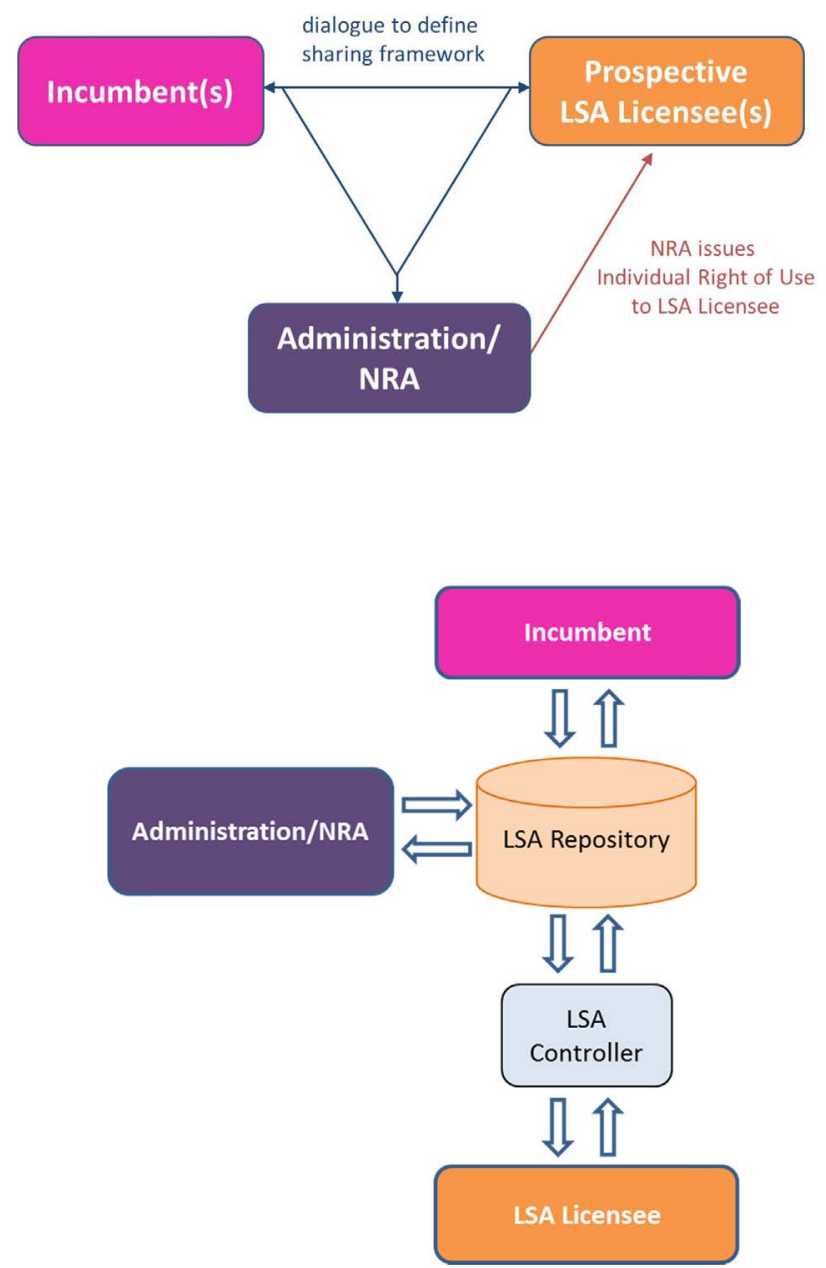

Fig. 1. The LSA approach: main actors and functional blocks.

Source: CEPT (2014b).

also be managed by the NRA, the incumbent or a trusted third party (CEPT, 2014b; AGCOM, 2016b).

\section{Licensed shared access in the $5 \mathrm{G}$ context}

The current interest in licensed shared access is driven by the intent to find additional sub-6 GHz spectrum to support 5G deployment (EC, 2016b). Licensed shared access would facilitate access for mobile broadband services in underutilised public sector spectrum (RSPG, 2013; CEPT, 2014a). In this regard, the $2.3 \mathrm{GHz}$ band and the $3.5 \mathrm{GHz}$ band are under scrutiny, respectively in the EU and the US (FCC, 2012; Khun-Jush et al., 2012; EC, 2014). Both the $2.3 \mathrm{GHz}$ band and the $3.5 \mathrm{GHz}$ band have already been identified, at international level, as suitable for the provision of mobile broadband services (ITU, 2012a; GSMA, 2013). Nevertheless, all spectrum internationally identified for the provision of mobile broadband services is only in part employed for this specific use. In many countries, several other services rely on that same spectrum (GSMA, 2015). In this regard, the $2.3 \mathrm{GHz}$ and the $3.5 \mathrm{GHz}$ bands are mainly used for military purposes in the EU and the US, respectively.

Against this background, the purpose of this section is to compare the LSA and the CUS regimes to understand to what extent the LSA regime enables spectrum sharing solutions which cannot be supported by existing spectrum sharing arrangements in the EU. Furthermore, a comparison is made between the LSA and the SAS regimes to clarify the differences between the approaches adopted in the EU and the US to reach the same objective of finding additional spectrum for mobile broadband services.

\subsection{The LSA and the CUS regimes: A comparison}

The CUS model is considered an attractive sharing regime to facilitate rapid access to spectrum. Under the CUS model, anyone can access the spectrum at very low or no fee. This would favour market entry and stimulate competitiveness. Such competitive environment would encourage investment and innovation in technologies and services, eventually expanding consumer choice (RSPG, 2011b). Nevertheless, the CUS model presents a major limitation, which restricts the suitable use cases for its 


\section{implementation.}

The CUS model does not guarantee protection from harmful interference and predictable QoS. Under the licence-exempt regime, access to spectrum is unrestricted and users are not requested to self-coordinate. Applications operate on a best effort (nointerference, no-protection) basis. Spectrum is subject to congestion and, consequently, there is no certainty over QoS. In cases of intense usage, QoS degradation may occur and users cannot claim protection from harmful interference. This is the reason why the licence-exempt access regime is generally implemented in very high spectrum bands, where congestion is less likely because of poor propagation properties (Cave \& Webb, 2015) and it is employed for applications whose spectrum use involves short range and low power transmissions, in short intervals. These conditions would ensure co-existence in the same band of different applications, with limited risk of producing harmful interference. Examples of these applications are: Ultra-Wide Band (UWB) devices (e.g. automotive radars); cordless telephony; garage door openers; baby monitors; microwave ovens; TV remote controls; Wi-Fi and Bluetooth, among other applications (RSPG, 2011b).

Similarly, under the light licensing regime, access to spectrum is unrestricted and it is often uncertain whether all users have registered. If single users/locations are not always known, generating interference is much more likely. Furthermore, although protection from harmful interference can sometimes be claimed, it can be difficult to identify the cause of interference. Given these circumstances, the light licensing regime is usually implemented in high frequency bands, whose poor propagation properties allow for provision of high data capacity over short distances (Tehrani et al., 2016). For instance, the light licensing regime is implemented in some EU countries to manage the use of the e-band, which include the 71-76 GHz and the 81-86 GHz bands (Wells, 2010).

Contrary to the CUS model, the LSA approach would restrict access to spectrum to a limited number of users. In particular, existing incumbent users would share spectrum with a certain number of secondary users. Secondary users would be provided with individual licences, which include specific sharing conditions. Both groups of users would have the right of protection from harmful interference and the conditions to provide services with predictable QoS. Under the LSA regime, existing users would lease part of their spectrum to new users, for a certain period of time, in exchange for a compensation, while maintaining control over spectrum in the long term. On one hand, incumbents would be interested in leasing spectrum in return for monetary gains or other advantages for instance, improved QoS or network performances. On the other hand, LSA licensees would be attracted by timely availability of spectrum and modest regulatory burden (Khun-Jush et al., 2012; ETSI, 2013; CEPT, 2014c).

Under the LSA approach, incumbents and LSA licensees are expected to set up a sharing framework for a period of time sufficient for LSA licensees to realise returns on investments (Plum Consulting, 2013). At the same time, it is assumed that LSA licensees would develop flexible business models, to ensure responsive adaptations to emerging technology and market conditions (Ericsson, 2016b). Radio spectrum users may incur in costs due to implementation of network technologies necessary to ensure the required QoS in a shared framework. This could be particularly true for incumbents, whose technologies are designed for exclusive spectrum use. Yet, financial compensations might be agreed between parties, depending on who is required to adopt interference-mitigation technologies.

In the context of $5 \mathrm{G}$, the CUS model may find suitable application in spectrum bands above $6 \mathrm{GHz}$, where the risk of congestion and, therefore, of producing harmful interference is relatively low, due to poor propagation properties. In particular, the CUS model may provide the right regulatory environment for the provision of mobile broadband services in specific high dense areas. Instead, the LSA model would offer mobile operators the opportunity to use portions of sub- $6 \mathrm{GHz}$ spectrum, which would not be otherwise accessible, for the provision of highly robust performances over long distances. The LSA model appears to be particularly attractive, if implemented in bands already identified at international level for mobile broadband services. Spectrum internationally identified for the provision of mobile broadband services creates the basis for global harmonisation, enabling economies of scale, global roaming, and reduced device complexity.

\subsection{The LSA and the SAS regimes: A comparison}

The LSA and the SAS regimes share the same basic logic, which is allowing the provision of mobile broadband services by using idle spectrum reserved to public sector uses. Nevertheless, these two regimes present three main differences, as shown below.

\subsubsection{Two-tier versus three-tier system}

First of all, the LSA system grants radio spectrum access to two categories of users, both on an individual basis. Instead, the SAS system has a three-tier structure: in addition to incumbents and secondary users, which are granted individual licences, the third category of general authorised access users would access the radio spectrum on a licence-exempt basis (Mueck et al., 2015). Although exempted from individual licensing, users belonging to the third tier are requested to register and provide certain geolocation information (FCC, 2015).

The first tier of the SAS system includes incumbent users, which are entitled to interference protection from all other users. The second tier is represented by the priority access users, with critical QoS needs, such as hospitals and public safety entities, which are allowed to access the $3.5 \mathrm{GHz}$ band under specific frequency, location and time sharing conditions. Priority access users are entitled to interference protection from the third category of general authorised access users. General authorised access users represent the third tier of the SAS system, which are allowed to opportunistically access the radio spectrum, when this is not used by incumbent and priority access users.

The SAS regime would allow for a denser use of the radio spectrum, compared to the LSA regime, by granting access to the radio spectrum to three groups of users. Nevertheless, the third tier of users may drive the SAS regime to a critical level of complexity, when it comes to managing interference issues, as further explained in the next sub-section. In particular, the use of the $3.5 \mathrm{GHz}$ 
band by three groups of users is coordinated by implementing spectrum sensing techniques, in addition to a geo-location database. However, database-assisted spectrum sensing may fail to guarantee that the information contained in the database reflects real-time spectrum usage. If the information contained in the database is incorrect, interference issues may arise when general authorised access users access the spectrum, generating uncertainties with regard to QoS for both incumbents and priority access users. According to Tehrani et al. (2016), the use of a geo-location database is more suitable for static spectrum sharing, which is the case of the LSA regime. Information on incumbent spectrum use included in the database is fixed and does not vary on a real-time basis.

\subsubsection{Static versus dynamic database}

Another relevant aspect which differentiates the LSA from the SAS regime regards the level of technical complexity, in particular with regard to the approach used to manage spectrum use by different categories of users. The LSA system is based on the creation of a centralised geo-location database, the LSA repository, containing information about incumbent radio spectrum usage. The LSA repository is a static database: incumbents provide a priori information, which means that incumbents' activities and, therefore, availability of spectrum for LSA licensees in terms of frequency, time and location is known upfront. Similarly, the SAS system would also include a geo-location database. However, the SAS geo-location database is dynamic. Each time a general authorised access user wants to access the spectrum, the SAS database determines which frequencies are available based on its geo-location information. Incumbent users would not provide any a priori information to the SAS database. Incumbent spectrum usage has to be determined by employing sensing technologies. In this regard, the SAS system results more complex than the LSA system, from a technical point of view, as it combines the use of a geo-location database with spectrum sensing techniques (Mueck et al., 2015).

Spectrum sensing is an activity whereby radio frequencies are continuously analysed in order to detect unused frequencies (FCC, 2015). When no signals are detected, the frequencies analysed are assumed to be usable by other services (ITU, 2012b; ETSI, 2015; Cave \& Webb, 2015). This activity is performed by employing Reconfigurable Radio Systems (RRSs), such as Software Defined Radio (SDR) and Cognitive Radio (CR), which are a combination of radio equipment and software. These technologies would find opportunities for spectrum access without interfering with incumbent users. Spectrum sensing is a very delicate activity, which could actually fail to detect existing signals. In case of active, but undetected transmissions, the problem of channel fading or shadowing may arise, which means that new services might interfere with existing ones (Akyildiz et al., 2011). Allowing more groups of users to access the spectrum increases the risk of service degradation for incumbents and priority access users. In case of signal collision at the expense of public services, such as defence or public safety, national public policy concerns might also arise. Furthermore, despite years of research efforts, RRS technology seems to be still in an emerging phase (Rysavy Research, 2012; Medeisis \& Minervini, 2013).

An effective spectrum sensing technique called cooperative spectrum sensing has recently gained attention for its capability to mitigate the problem of channel fading or shadowing, and, therefore, reduce the risk of interference. In cooperative spectrum sensing, secondary users would share information regarding their observations on the incumbent's spectrum usage, leading to a more accurate scanning and detection of existing signals (Akyildiz et al., 2011; Subhedar \& Birajdar, 2011; Kim, 2015). However, in this context, the free-riding phenomenon may arise. New users may egoistically decide not to participate in spectrum sensing activity, it being a time and energy consuming activity, and to benefit from others' sensing results (Dai \& Wu, 2014). In case of freeriding, there is a greater risk of interference, as the probability that signals are not detected increases (Tamilarasan \& Kumar, 2016). The free-riding phenomenon represents an issue for enforcement mechanisms because of the difficulty of identifying the free-rider.

Spectrum sensing would also raise security and privacy issues. With regard to security, a well-documented problem in cooperative spectrum sensing is spectrum sensing data falsification (SSDF). SSDF occurs when an RRS user falsifies spectrum sensing results, degrading the accuracy of spectrum usage detection and, consequently, increasing the risk of interference between incumbents and new users (Althunibat et al., 2014). In terms of privacy issues, cooperative spectrum sensing may compromise secondary users' location privacy because sharing spectrum sensing results reveal information on users' location (Zina, Hasna, Hamila \& Hamdi, 2016; Grissa et al., 2016).

Privacy issues may also arise in the case of the LSA regime. Incumbents might manifest privacy concerns with regard to a priori information on their radio spectrum usage provided for the creation of the LSA repository (FUB, 2016). The database would contain information related to spectrum use in the spatial, frequency and time domains, and degree of susceptibility to interference. This information may be particularly sensitive for public sector users, such as military systems, as experiencing a breach of privacy might represent a threat to national security and interests (Park \& Reed, 2013; Bahrak, Bhattarai, Ullah, Park, Reed \& Gurney, 2014; Clark \& Psounis, 2016). Likewise, LSA users would be required to share information on their spectrum usage (CEPT, 2015). It must be said that technical solutions have been developed to mask the true activity of radio spectrum users and restrict the amount of information to be made available (ETSI, 2015; CEPT, 2015).

Enforcement procedures, whether public or private (Weiss, Lehr, Altamimi \& Cui, 2012), have to be designed for the LSA regulatory regime and other licensed shared-access regimes to function properly (Rysavy Research, 2012; Cui et al., 2014), taking into due account the free-riding problem, as well as security and privacy concerns. Enforcement mechanisms are necessary to make sure that incumbents and secondary users comply with agreed frequency, location and time sharing conditions, and to safeguard privacy and security of sensitive information, by providing incentives for compliance and/or punishments for non-compliance. Enforcement is key of any property rights regime and the challenge of enforcing usage property rights is not new to spectrum management. However, these new forms of spectrum sharing bring additional challenges that need to be tackled when designing enforcement procedures (Cave \& Webb, 2015). 


\subsubsection{Commercial transaction versus auction procedure}

A third major difference between the LSA and the SAS regimes regards the authorisation methodology implemented to assign licences to secondary users. Under the LSA regime, incumbents would lease part of their spectrum to new users, for a certain period of time, in exchange for a compensation. On the contrary, licences for SAS priority access would be granted by means of auction procedures (FFC, 2015; Mueck et al., 2015).

LSA users would obtain access to radio spectrum, at relatively low costs, by means of commercial transactions with incumbents, without going through lengthy and costly auction procedures (ETSI, 2013; Gundlach, 2014). Radio spectrum users would incur bargaining costs in order to reach an agreement. However, costs of negotiation are to be evaluated relative to the costs that radio spectrum users would incur if access to the radio spectrum were regulated by other means. If the NRA decided for reallocation of a certain frequency band, existing users would bear the costs of re-farming. The process of freeing up spectrum is well documented as being controversial, lengthy and time-consuming (e.g. Khun-Jush et al., 2012). If the regulator decided for auctioning that frequency band, new users would bear the costs of participating in the auction. In this respect, evidence has shown that acquiring radio spectrum licences by participating in auctions requires large initial investments. This high entry barrier would be lessened by implementing the LSA regime, whereby access to spectrum is obtained by negotiating an agreement with incumbents. In the case of the $2.4 \mathrm{GHz}$ band, the opportunity to obtain access to spectrum by means of commercial agreements with incumbents may result attractive not only for existing mobile operators, but also for new entrants (AGCOM, 2016b). New entrants may be able to enter the market, obtaining access to spectrum easily and at lower costs compared to auction procedures (Digital Europe, 2013). In this regard, the LSA regime seems to be more attractive compared to the SAS regime, where licences for priority access would be granted by means of auction procedures.

Conducting an auction for assigning LSA licences has also been proposed (Digital Europe, 2013; Marsden \& Ihle, 2016). According to Marsden \& Ihle (2016: 6), letting radio spectrum users negotiate sharing agreements would result in unsuccessful negotiations, because of the problem of informational asymmetry in a thin market. Radio spectrum users would fail to reach a mutually beneficial agreement because incumbents and LSA users would be incentivised to give a biased representation of their respective costs and willingness to pay. The auction model proposed by Marsden \& Ihle to deal with the problem of informational asymmetry resembles the structure of the US incentive auction for the $600 \mathrm{MHz}$ band. Although the problem of informational asymmetry is critical and has to be taken into account, NRAs need to assess whether adopting such auction mechanism would cause unnecessary delays. The US incentive auction was designed in 2010 and began in March 2016 (FCC, 2016b). It has not been completed yet (FCC, 2016c) and it has been delayed several times (Standeford, 2013; Youell, 2014).

\section{Concluding remarks}

This article provided a comparison of the LSA regime with the CUS and SAS regimes to clarify the relevance of LSA in the context of 5G. The investigation suggests that the LSA regime would enable a new way of sharing spectrum, which is not satisfied by the CUS approach. Contrary to the CUS approach, the LSA regime allows incumbents and LSA users to share spectrum on a licensed basis. All users have the right of protection from harmful interference and the legal obligation to comply with sharing conditions included in the licences. Since access to spectrum is restricted to a limited number of users, the LSA regime can find application in low spectrum bands, notwithstanding the relatively high risk of interference.

In the context of $5 \mathrm{G}$, the LSA regime appears suitable to facilitate access to spectrum bands below $6 \mathrm{GHz}$. In these bands, refarming is unlikely at least in the short-term, because incumbents are unable or lack the incentives to make unused spectrum frequencies available for new uses. Therefore, sharing spectrum on a licensed basis appears to be an effective way to give mobile operators the opportunity to access highly demanded spectrum with attractive propagation properties essential for certain $5 \mathrm{G}$ use cases.

In comparison with the SAS regime, the investigation suggests that the LSA regime can be implemented quicker and with less effort than the SAS regime, because of its lower level of technical complexity. In theory, the SAS regime would lead to a denser use of the radio spectrum, compared to the LSA regime, by allowing three groups of users to access the spectrum. Nevertheless, the technology necessary to guarantee interference-free coexistence between these groups of users seems not to be ready yet. Despite years of research efforts, the current level of technology development related to spectrum sensing techniques does not guarantee protection from harmful interference.

Based on this investigation, it can be concluded that there are opportunities to implement the LSA regime to open already occupied, but underused frequency bands in the sub- $6 \mathrm{GHz}$ spectrum in support of timely deployment of 5G. Nevertheless, the LSA regime is expected to be overtaken by the SAS regime in the long term, as spectrum sensing techniques are further refined.

This investigation focuses on the opportunity to implement the LSA regime in low spectrum bands characterised by fragmented allocations where re-farming results unlikely. However, it should not be excluded the possibility to allow for licensed shared access in higher spectrum bands, if that is found to be necessary to support certain $5 \mathrm{G}$ use cases. Individual licensing, whether allowing for exclusive or shared access to spectrum, will remain important to guarantee regulatory certainty in support of investment for $5 \mathrm{G}$ deployment and to meet connectivity needs such as certain availability of spectrum and predictable QoS. 5G calls for a flexible management approach to radio spectrum, which combines different spectrum access regimes to accommodate diverse $5 \mathrm{G}$ use cases.

\section{Acknowledgements}

I would like to thank the anonymous referee for helpful comments. In addition, I would like to state that a previous version of this 
paper was co-authored with Professor Gérard Pogorel, Telecoms ParisTech, and Professor Erik Bohlin, Chalmers University of Technology, and presented at the 26th European Regional Conference of the International Telecommunications Society (ITS), San Lorenzo de El Escorial, Spain, 24-27 June 2015 and at the Regional Conference of the International Telecommunications Society (ITS), Los Angeles, California, USA, 27-28 October 2015.

\section{References}

4G Americas (2015). 5G White Paper. Retrieved March 13, 2017 from 〈http://www.5gamericas.org/files/6514/3930/9262/4G_Americas_5G_Spectrum_ Recommendations_White_Paper.pdf).

5G Manifesto for timely deployment of 5G in Europe (2016). Retrieved January 10, 2017, from 〈https://ec.europa.eu/digital-single-market/en/news/commissioneroettinger-welcomes-5g-manifesto $>$.

AGCOM (2016a). Al via consultazione pubblica su modalità di accesso condiviso allo spettro (LSA), Press Release. Retrieved January 10, 2017, from 〈https://www. agcom.it/-/consultazione-pubblica-concernente-l-accesso-condiviso-allo-spettro-in-modalita-licensed-shared-access-lsa-per-sistemi-terrestri-di-comunicazionielet>.

AGCOM (2016b). Attachment B to Resolution n. 121/16/CONS Consultazione pubblica concernente l'accesso condiviso allo spettro in modalità "licensed shared access" (LSA) per sistemi terrestri di comunicazioni elettroniche. Retrieved March 19, 2017, from 〈https://www.agcom.it/documents/10179/4364847/Allegato +2-5-2016+1462180029746/530cd90b-58d0-40cc-ac34-ba98aea13451?version=1.0 $>$.

Akyildiz, I. F., Lo, B. F., \& Balakrishnan, R. (2011). Cooperative spectrum sensing in cognitive radio networks: A survey. Physical Communication, 1, 40-62.

Althunibat, S., Di Renzo, M. \& Granelli, F. (2014). Robust Algorithm against Spectrum Sensing Data Falsification Attack in Cognitive Radio Networks, In Proceedings of the IEEE 79th Vehicular Technology Conference, pp. 1-5. DOI: http://dx.doi.org/10.1109/VTCSpring.2014.7023078.

Bahrak, B., Bhattarai, S., Ullah, A., Park, J.-M., Reed, J. \& Gurney, D. (2014). Protecting the primary users' operational privacy in spectrum sharing, In Proceedings of IEEE International Symposium on Dynamic Spectrum Access Networks (DYSPAN), pp. 236-247. DOI: http://dx.doi.org/10.1109/DySPAN.2014.6817800.

Bauer, J. M. (2010). Regulation, public policy, and investment in communications infrastructure. Telecommunications Policy, 34(1-2), 65-79. http://dx.doi.org/10.1016/j.telpol.2009.11.011.

Bauer, J. M., \& Bohlin, E. (2008). Form static to dynamic regulation. Recent developments in US. Telecommunications Policy, Intereconomics, 43(1), 38-50.

Bauer, J. M. (2002). A comparative Analysis of Spectrum Management Regimes. Paper presented at the 30th Research Conference on Communication, Information and Internet Policy, Alexandria, VA, USA, 28-30.

Bauer, J.M. \& Shim, W. (2012). Regulation and digital innovation: Theory and evidence. Paper presented at the 23rd European Regional Conference of the International Telecommunication Society, Vienna, Austria.

Bunel, A. \& Lescop, D. (2012). Shared access, cognitive radio and transition issues. Paper presented at the 19th Biennial Conference of the International Telecommunication Society, Bangkok, Thailand.

Cambini, C., \& Garelli, N. (2011). Evaluation of the opportunity cost of the spectrum: Application to the digital dividend. Telecommunications Policy, 35(7), $633-649$.

Cave, M., \& Webb, W. (2015). Spectrum management using the aimwaves for maximum social and economic benefit Cambridge: Cambridge University Press.

Cave, M., Doyle, C., \& Webb, W. (2007). Essentials of modern spectrum management Cambridge: Cambridge University Press. http://dx.doi.org/10.1017/ CBO9780511536724.

Cave, M. (2002). Review of Radio Spectrum Management. An independent review for Department of Trade and Industry and HM Treasury.

CEPT (2013). Licensed Spectrum Access opens new opportunities, ECC Newsletter. Retrieved January 10, 2017, from 〈http://apps.ero.dk/eccnews/october-2013/ index.html $\rangle$.

CEPT (2014a). Trends and principles in spectrum management, PowerPoint Presentation at CEPT Workshop on European Spectrum Management and Numbering. Retrieved January 10, 2017, from 〈http://www.cept.org/files/1051/Workshops/CEPT\%20workshop\%20june\%202014/3-2-Trends_principles_examples_. spectrum\%20management.pptx $\rangle$.

CEPT (2014b). ECC Report 205 Licensed Shared Access (LSA).

CEPT (2014c). Draft ECC Decision (14)BB, Harmonised technical and regulatory conditions for the use of the band 2300-2400 MHz for MFCN.

CEPT (2015). ECC Recommendation 15(04) Guidance for the implementation of a sharing framework between MFCN and PMSE within 2300-2400 MHz.

CEPT (2016). LSA Implementation, website. Retrieved January 10, 2017, from 〈http://www.cept.org/ecc/topics/lsa-implementation/ $>$.

Cisco (2014). Cisco Visual Networking Index: Global Mobile Data Traffic Forecast Update, 2013-2018, White Paper.

Cisco (2016a). The Zettabyte Era - Trends and Analysis, White Paper.

Cisco (2016b). Cisco Visual Networking Index: Global Mobile Data Traffic Forecast Update, 2015-2020, White Paper.

Clark, M. \& Psounis, K. (2016). Can the privacy of primary networks in shared spectrum be protected? In Proceedings of the 35th Annual IEEE International Conference on Computer Communications, pp. 1-9. DOI: http://dx.doi.org/10.1109/INFOCOM.2016.7524587.

Cui, L., Gomez, M.M. \& Weiss, M.B.H. (2014). Dimensions of cooperative spectrum sharing: rights and enforcement, In Proceedings of the New Frontiers in Dynamic Spectrum Access Networks (DySPAN) Conference, pp. 1-11. DOI: http://dx.doi.org/10.1109/DySPAN.2014.6817825.

Dai, Y \& Wu, J. (2014). Cooperation Scheme for Distributed Spectrum Sensing in Cognitive Radio Networks, ICST Transactions Preprint, EAI Endorsed Transactions on Mobile Communications and Applications, 14(4), 1-11.Deloitte (2014). The Impact of Licensed Shared Use of Spectrum, a report for the GSMA prepared in collaboration with Realwireless.

EC (2012). Promoting the shared use of radio spectrum resources in the internal market, Communication from the Commission to the European Parliament, the Council, the European Economic and Social Committee and the Committee of the Regions COM (2012) 478.

EC (2014). Mandate to CEPT to develop harmonised technical conditions for the $2300-2400 \mathrm{MHz}$ ( $2.3 \mathrm{GHz}$ ) frequency band in the EU for the provision of wireless broadband electronic communications services. Retrieved January 10, from 〈https://ec.europa.eu/digital-single-market/en/news/radio-spectrum-ceptmandates-0 0 .

EC (2015). A Digital Single Market Strategy for Europe, Communication from the Commission to the European Parliament, the Council, the Europe an Economic and Social Committee and the Committee of the Regions COM (2015) 192.

EC (2016a). 5G Developments accompanying the document Communication from the Commission to the European parliament, the Council, the European Economic and Social Committee and the Committee of the Regions 5G for Europe: An Action Plan, Commission Staff Working Document SWD (2016) 306.

EC (2016b). Proposal for a Directive of the European Parliament and of the Council establishing the European Electronic Communications Code COM(2016) 590.

EC (2016c). Better regulations for innovation - driven investment at EU level, 〈https://ec.europa.eu/research/innovation-union/pdf/innovrefit_staff_working_ document.pdf , Commission Staff Working Document. Retrieved January 10, 2017, from 〈https://ec.europa.eu/research/innovation-union/pdf/innovrefit_ staff_working_document.pdf $\rangle$.

ECC (2009). Light licensing, licence-exempt and the commons. Report.

ECC (2011). Description of practices relative to trading of spectrum rights of use. Report.

EP \& Council (2002). Directive 2002/20/EC of the European Parliament and of the Council of 7 March 2002 on the authorisation of electronic communications networks and services (Authorisation Directive).

EP \& Council (2012). Decision 243/2012/EU of the European Parliament and of the Council of 14 March 2012 establishing a multiannual radio spectrum policy programme.

Ericsson (2016a). 5G Radio Access, White Paper. Retrieved March 10, 2017, from 〈https://www.ericsson.com/res/docs/whitepapers/wp-5g.pdf〉.

Ericsson (2016b). A vision of the 5G core: flexibility for new business opportunities. Retrieved March 10, 2017, from 〈https://www.ericsson.com/res/thecompany/ 
docs/publications/ericsson_review/2016/etr-5G-core-vision.pdf $\rangle$.

ETSI (2013). Electromagnetic compatibility and Radio Spectrum Matters (ERM); System Reference Document (SRdoc); Mobile broadband services in the 2300 MHz$2400 \mathrm{MHz}$ frequency band under Licensed Shared Access regime, Technical Report No. 103 113 V.1.1.1.

ETSI (2015). Reconfigurable Radio Systems (RRS); System architecture and high level procedures for operation of Licensed Shared Access (LSA) in the 2300 MHz$2400 \mathrm{MHz}$ band. Technical Report No. 103 235 V.1.1.1.

Faulhaber, G.R. \& Farber D. (2002). Spectrum Management: Property rights, Markets, and the Commons, Working Paper 02-12, ICT Regulation Toolkit. Retrieved January 10, 2017, from 〈http://www.ictregulationtoolkit.org/en/toolkit/docs/Document/3629〉.

FCC (2012). Notice of proposed rulemaking and order in the Matter of Amendment of the Commission's Rules with Regard to Commercial Operations in the 3550$3650 \mathrm{MHz}$ Band. Retrieved January 10, 2017, from 〈https://www.fcc.gov/document/enabling-innovative-small-cell-use-35-ghz-band-nprm-order .

FCC (2015). Report and order and second further notice of proposed rulemaking in the matter of Amendment of the Commission's Rules with Regard to Commercial Operations in the 3550-3650 MHz Band. Retrieved January 10, 2017, from 〈https://apps.fcc.gov/edocs_public/attachmatch/FCC-15-47A1.pdf〉.

FCC (2016a). FCC Adopts Rules to Facilitate Next Generation Wireless Technologies, News Release and Report and Order. Retrieved January 10, 2017, from 〈https://www.fcc.gov/document/fcc-adopts-rules-facilitate-next-generation-wireless-technologies〉.

FCC (2016b). Broadcast Incentive Auction, Website. Retrieved January 10, 2017, from 〈https://www.fcc.gov/about-fcc/fcc-initiatives/incentive-auctions\#blockmenu-block-4〉.

FCC (2016c). Incentive Auction Dashboard, Website. Retrieved January 10, 2017, from 〈https://auctiondata.fcc.gov/public/projects/1000〉.

Federal Register (2008). Spectrum Sharing Innovation Test Bed. Retrieved March 19, 2017, from 〈https://www.gpo.gov/fdsys/pkg/FR-2008-02-05/pdf/E8-2050. pdf $\rangle$.

Foster McLean \& Co. in collaboration Cave, M. \& Jones, R. W. (2007). Radio Spectrum Management, Module 5, Executive Summary, ICT Regulation Toolkit.

FUB (2016). LSA pilot - Sharing analysis in a live LTE network in the 2.3-2.4 GHz band. Test configuration and results, Report. Retrieved January 10, 2017, from 〈http://www.mise.gov.it/images/stories/documenti/Report_LSA_05_rev.pdf).

Grissa, M., Yavuz, A. \& Hamdaoui, B. (2016). An efficient technique for protecting location privacy of cooperative spectrum sensing users, Proceedings of the IEEE Conference on Computer Communications Workshops, pp. 1-4. DOI: http://dx.doi.org/10.1109/INFCOMW.2016.7562209.

GSMA (2013). Licensed Shared Access (LSA) and Authorised Shared Access (ASA), Public Policy Position.

GSMA (2014). The Cost of Spectrum Auction Distortions. Review of spectrum auction policies and economic assessment of the impact of inefficient outcomes.

GSMA (2015). A Guide to WRC-15 Agenda Item 1.1. Retrieved March 19, 2017, from 〈http://www.gsma.com/spectrum/wp-content/uploads/2015/07/Guide-toWRC-15-AI-1.1.pdf $\rangle$.

Gundlach, M. (2014). Overview of LSA activities in ETSI, PowerPoint Presentation at European Conference on Networks and Communications, Bologna, Italy Retrieved January 10, 2017, from 〈http://www.ict-ras.eu/index.php?option=com_content \& view=article \& id=5 \& Itemid=0 \& jsmallfib=1 \& dir=JSROOT \%5CMeetings/EuCNC+Workshop+(23June2014) \& download_file=JSROOT\%5CMeetings/EuCNC+Workshop+(23June2014)/LSA++standardization +overview.pdf $\rangle$.

Ingenious Consulting Network (2011). Authorised Shared Access (ASA). An evolutionary spectrum authorisation scheme for sustainable economic growth and consumer benefit. Paper presented at the 72nd Meeting of the WG FM, Miesbach, Germany.

ITU (2012b). Economic Aspects of Spectrum Management, Report ITU-R SM. 2012-1.

ITU (2012a). Spectrum for IMT. Retrieved March 19, 2017, from 〈https://www.itu.int/ITU-D/tech/MobileCommunications/Spectrum-IMT.pdf〉.

ITU (2015a). Recommendation ITU-R M.2083-0 IMT Vision - Framework and overall objectives of the future development of IMT for 2020 and beyond.

ITU (2015b). Technology trends of active services in the frequency range 275-3000 GHz, Report No. SM.2352-0.

ITU (2015c). IMT Vision - Framework and overall objectives of the future development of IMT for 2020 and beyond, Recommendation ITU-R M.2083-0.

Khun-Jush, J., Bender, P., Deschamps, B. \& Gundlach, M. (2012). Licensed shared access as complementary approach to meet spectrum demands: Benefits for next generation cellular systems. Paper presented at ETSI Workshop Reconfigurable Radio Systems, Cannes, France.

Kim, S. (2015). Learning based spectrum sharing algorithms by using coopetition game approach. Wireless Personal Communications, 82(3), $1799-1808$.

Leibovitz, J. (2015). Breaking Down Barriers to Innovation in the $3.5 \mathrm{GHz}$ Band, FCC Blog. Retrieved March 26, 2017, from 〈https://www.fcc.gov/news-events/blog/ 2015/04/21/breaking-down-barriers-innovation-35-ghz-band).

Lie, E. (2004). Radio Spectrum Management for a Converging World. Paper prepared for the ITU Workshop on Radio Spectrum Management for a Converging World, ITU New Initiative programme, Geneva, Switzerland.

Marcus, J. S., Pogorel, G., \& Pujol, F. (2013). The radio spectrum: a shift in paradigms? Introduction. Communications \& Strategies, 90(Q2), 11-16.

Marsden, R. \& Ihle, H.-M. (2016). Mechanisms to Incentivize Shared-Use of Spectrum, NERA Economic Consulting Report.

Medeisis, A., \& Minervini, L. F. (2013). Stalling innovation of cognitive radio: The case for a dedicated Frequency band. Telecommunications Policy, 37(2-3), $108-115$.

Melody, W. H., \& Lemstra, W. (2011). Liberalization in radio spectrum management. , in: Finger, M., \& Kunneke, R. W. (Eds.). (2011). International handbook of Network Industries. The liberalization of infrastructure . Cheltenham, UK: Edward Elgar, 123-143.

Mueck, M.D.; Srikanteswara, S. \& Badic, B. (2015). Spectrum Sharing: Licensed Shared Access (LSA) and Spectrum Access System (SAS), Intel White Paper.

Nicita, A., \& Rossi, M. A. (2013). Spectrum crunch vs. spectrum sharing: Exploring the "Authorised Shared Access" model. Communications \& Strategies, 90(Q2), $17-40$.

Noam, E. M. (1998). Spectrum auctions: Yesterday's heresy, today's orthodoxy, tomorrow's anachronism. The Journal of Law and Economics, 41(2), 765-790. http://dx.doi.org/10.1086/467412.

Noam, E.M. (2003). The Third Way for Spectrum, Financial Times, Retrieved January 10, 2017, from $\langle$ http://msl1.mit.edu/ESD10/docs/ft_spectrum_policy_e_ noam_mar 14 2003.pdf $\rangle$.

Oniki, H. (2009). Designing a system for reallocation of spectrum: Implications for a conceptual study. Osaka-Gakuin Review of Economics, 23(2), 1-82.

Palola, M., Matinmikko, M., Prokkola, J., Mustonen, M., Heikkilä, M., ... Eiska, K. (2014). Live field trial of Licensed Shared Access (LSA) concept using LTE network in $2.3 \mathrm{GHz}$ band, In Proceedings of IEEE International Symposium on Dynamic Spectrum Access Networks (DYSPAN).

Park, J.-M. \& Reed, J.H. (2013). Ensuring Operational Privacy of Primary Users in Geolocation Database-Driven Spectrum Sharing, Summary Report for Task 1: Prior-Art Privacy Preserving Databases and Threat Models for NTIA.

Peha, J. M. (2009). Sharing Spectrum Through Spectrum Policy Reform and Cognitive Radio. Proceedings of the IEEE, 97(4), 708-719.

Plum Consulting (2013). The economic benefits of LSA in $2.3 \mathrm{GHz}$ in Europe. Report for Ericsson, NSN and Qualcomm.

PolicyTracker (2016). Potential 5G bands. Retrieved March 9, 2017, from 〈https://www.policytracker.com/bands/5g-bands $\rangle$.

Prasad, R., \& Sridhar, V. (2014). The dynamics of spectrum management: Legacy technology, and economic Oxford: Oxford University Press.

RSPG (2009). Radio spectrum policy group report on assignment and pricing methods.

RSPG (2011a). Opinion on Cognitive Technologies.

RSPG (2011b). Report on Collective Use of Spectrum (CUS) and other spectrum sharing approaches.

RSPG (2013). Opinion on Licensed Shared Access.

RSPG (2015). Opinion on Common Policy Objectives for WRC-15.

RSPG (2016). Strategic Roadmap towards $5 \mathrm{G}$ for Europe, Opinion on spectrum related aspects for next-generation wireless systems (5G).

Rysavy, P. (2014). Challenges and considerations in defining spectrum efficiency. Proceedings of the IEEE, 102(3), 386-392.

Rysavy Research (2012). Spectrum Sharing. The Promise and The Reality, Report.

Sappington, D. E. M., \& Weisman, D. L. (1996). Designing incentive regulation for the telecommunications industry Cambridge, MA: The MIT Press.

Standeford, D. (2013). FCC delays spectrum incentive auction until 2015, PolicyTracker. Retrieved January 10, 2017, from 〈https://www.policytracker.com/ headlines/fcc-delays-spectrum-incentive-auction-until-2015/?searchterm=None $\rangle$.

Subhedar, M., \& Birajdar, G. (2011). Spectrum sensing techniques in cognitive radio networks: A survey, International. Journal of Next-Generation Networks, 3(2), 37-51. http://dx.doi.org/10.5121/ijngn.2011.3203. 
Tamilarasan, S., \& Kumar, P. (2016). Dynamic resource allocation with imperfect channel sensing - Heterogeneous services in cognitive radio network. International Journal of Engineering Technology, Management and Applied Sciences, 4(7), 1-6.

Tehrani, R. H., Vahid, S., Triantafyllopoulou, D., Lee, H., \& Moessner, K. (2016). Licensed spectrum sharing schemes for mobile operators: A survey and outlook. IEEE Communications Surveys and Tutorials, 18(4), 1-33.

Webb, W. (2008). Licensing Spectrum. Retrieved March 30, 2017, from 〈https://www.policytracker.com/headlines/Webb\%20Licensing \%20 Spectrum\%20v1.pdf〉. Weiss, M. B. H., Lehr, W., Altamimi, M. \& Cui, L. (2012). Enforcement in Dynamic Spectrum Access Systems. Proceedings of 2012 TPRC, pp. 1-34.

Wells, J. (2010), Light Licensing. Light licensing benefits of the 71-76 \& 81-86 GHz frequency bands, E-Band Communications Corp. Retrieved March 30, 2017, from 〈http://www.e-band.com/get.php?f.848〉.

Werbach, K., \& Mehta, A. (2014). The spectrum opportunity: Sharing as the solution to the wireless crunch, International. Journal of Communication, 8, 128-149.

Wheeler, T. (2016). Use of Spectrum Bands Above 24 GHz for Mobile Radio Services, Statement of FCC Chairman Tom Wheeler. Retrieved March 19, 2017, from 〈https://apps.fcc.gov/edocs_public/attachmatch/DOC-340301A2.pdf〉.

Wilkins, J. \& Knapp, J. (2016). Continuing Momentum in the $3.5 \mathrm{GHz}$ band, FCC Blog post. Retrieved January 10, 2017, from 〈https://www.fcc.gov/news-events/ blog/2016/05/17/continuing-momentum-35-ghz-band $\rangle$.

Yang, A., Lee, D., Hwang, J., \& Shin, J. (2013). The Influence of regulations on the efficiency of telecommunications operators: A meta-frontier analysis. Telecommunications Policy, 37(11), 1071-1082.

Youell, T. (2014). Incentive auction delayed for another year, PolicyTracker. Retrieved January 10, 2017, from 〈https://www.policytracker.com/headlines/incentiveauction-delayed-for-another-year/?searchterm=Incentive\%20auction\%20delayed\%20for\%20another\%20year $\rangle$.

Zina, C., Hasna, M., Hamila, R., \& Hamdi, N. (2016). Location privacy preservation in secure crowdsourcing-based cooperative spectrum sensing. EURASIP Journal on Wireless Communications and Networking, 85, 1-11. http://dx.doi.org/10.1186/s13638-016-0567-7. 